\title{
Electrical treeing in a glassy epoxy resin - the filamentary tree and the PD tree
}

DOI:

10.1109/CEIDP.2017.8257517

\section{Document Version}

Accepted author manuscript

Link to publication record in Manchester Research Explorer

\section{Citation for published version (APA):}

Zheng, H., \& Rowland, S. (2018). Electrical treeing in a glassy epoxy resin - the filamentary tree and the PD tree. In IEEE Conference on Electrical Insulation and Dielectric Phenomena (CEIDP), https://doi.org/10.1109/CEIDP.2017.8257517

\section{Published in:}

IEEE Conference on Electrical Insulation and Dielectric Phenomena (CEIDP),

\section{Citing this paper}

Please note that where the full-text provided on Manchester Research Explorer is the Author Accepted Manuscript or Proof version this may differ from the final Published version. If citing, it is advised that you check and use the publisher's definitive version.

\section{General rights}

Copyright and moral rights for the publications made accessible in the Research Explorer are retained by the authors and/or other copyright owners and it is a condition of accessing publications that users recognise and abide by the legal requirements associated with these rights.

\section{Takedown policy}

If you believe that this document breaches copyright please refer to the University of Manchester's Takedown Procedures [http://man.ac.uk/04Y6Bo] or contact uml.scholarlycommunications@manchester.ac.uk providing relevant details, so we can investigate your claim.

\section{OPEN ACCESS}




\title{
Electrical treeing in a glassy epoxy resin - the filamentary tree and the PD tree
}

\author{
Hualong ZHENG, Simon M. Rowland \\ The University of Manchester \\ School of Electrical and Electronic Engineering \\ Manchester, M13 9PL, UK
}

\begin{abstract}
Two types of electrical trees have been observed to grow in a glassy epoxy resin of needle-plane geometry under $50 \mathrm{~Hz}$ AC voltage. They differ in their constituent channel radii and the associated partial discharge activity. The so-called 'filamentary tree' has finer channels and much smaller discharge magnitudes than the 'PD tree'. This work describes an electrical treeing process containing a clear transition from filamentary tree growth to PD tree growth with associated changes to partial discharge measurements. Apart from emphasizing the importance of recognizing tree channel thickness, it provides experimental evidence for an electro-mechanical treeing process in which filamentary channel propagation is followed by enlargement of the channel radius by partial discharges. Moreover, the PD characteristics during the transient stage are assessed. The magnitude of partial discharges during the transition stage was found to be polarity dependent.
\end{abstract}

Keywords-electrical tree, partial discharge, filamentary tree

\section{INTRODUCTION}

In solid dielectrics, the term 'electrical tree' is used to describe a broad family of physical defects made up of interconnected hollow tubules grown under high electrical stress [1]. Electrical trees can be further referred to as branch, bush or bush-branch trees, based on their morphology and visual similarity to their botanical namesakes. They are also characterized as electrically conducting or non-conducting artifacts based on their conductivity relative to the dielectric [2]. However, the radii of constituent tree channels are rarely used to classify trees.

It has been widely recognized that micro-cracks near an electrode provide favorable conditions for partial discharge excitation and consequently promote the initiation of electrical tree growth. In laboratory tests, where a metallic protrusion is part of the electrode geometry, cracks are normally regarded as a consequence of the residual mechanical stress between the electrode and the dielectric resulting from casting and thermal history [3]. However, it has been proposed that such a 'crack' can form, not only at the electrode but also at existing tree tips, due to electrofracture mechanics [4]. These cracks, visible or not, may exist in front of a tree tip and thus lead the growth of a PD channel. For example, in a branch tree, the tree trunk can be tens of micrometers wide, whereas the tree tip can be around one micrometer [1]. The difference in the radius of tree channels may suggest distinct mechanisms dominating their formation, as, for example, the inception voltage of gas discharge in tree channel depends on the channel radius [5].
To emphasize the importance of tree channel radius, this work describes a two-stage electrical treeing process observed in a glassy epoxy resin specimen of needle-plane geometry. In this case, under the applied AC voltage, filamentary tree channels firstly grew without detectable partial discharges. Later, wider tree channels started to develop from the tree 'root' to to the tree tips with accompanying increased partial discharge magnitudes (this stage is hereafter called PD treeing). Through detailed optical and PD measurements, the relationship between growth in tree length, branch diameter and partial discharge activity is determined.

\section{EXPERIMENTAL}

The samples were of a classical needle-plane geometry with $1 \mathrm{~mm}$ electrode separation. The needle (Ogura) electrode having a tip radius of $3 \mu \mathrm{m}$ and a tip taper angle of $30^{\circ}$ was cast in a $22 \mathrm{~mm} \times 22 \mathrm{~mm} \times 20 \mathrm{~mm}$ epoxy resin cuboid which was made of Araldite LY5052/Aradur 5052 (from Huntsman). After 24 hours curing at room temperature curing and postcuring at $100{ }^{\circ} \mathrm{C}$ for 4 hours, the resin had a glass transition temperature of $120-134{ }^{\circ} \mathrm{C}$.

Figure 1 shows a schematic of the experimental setup. The electrical treeing test was conducted at room temperature. $15 \mathrm{kV}_{\mathrm{P}}$ (peak magnitude), $50 \mathrm{~Hz}$ AC voltage was applied to the needle electrode from an HV amplifier (Trek®). The bottom surface of the sample was clamped to a brass plate acting as the ground electrode and the tested sample was immersed in a silicone oil bath. The treeing process was monitored and recorded through a CCD camera with a backlight. Partial discharge measurements were performed using an Omicron MPD 600, with a balanced circuit for noise reduction.

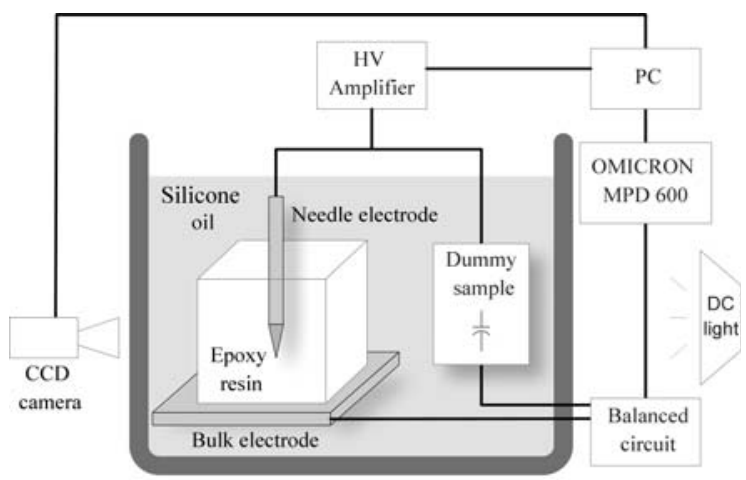

Figure 1. Experimental setup for real-time imaging of electrical tree growth and simultaneous partial discharge measurement. 


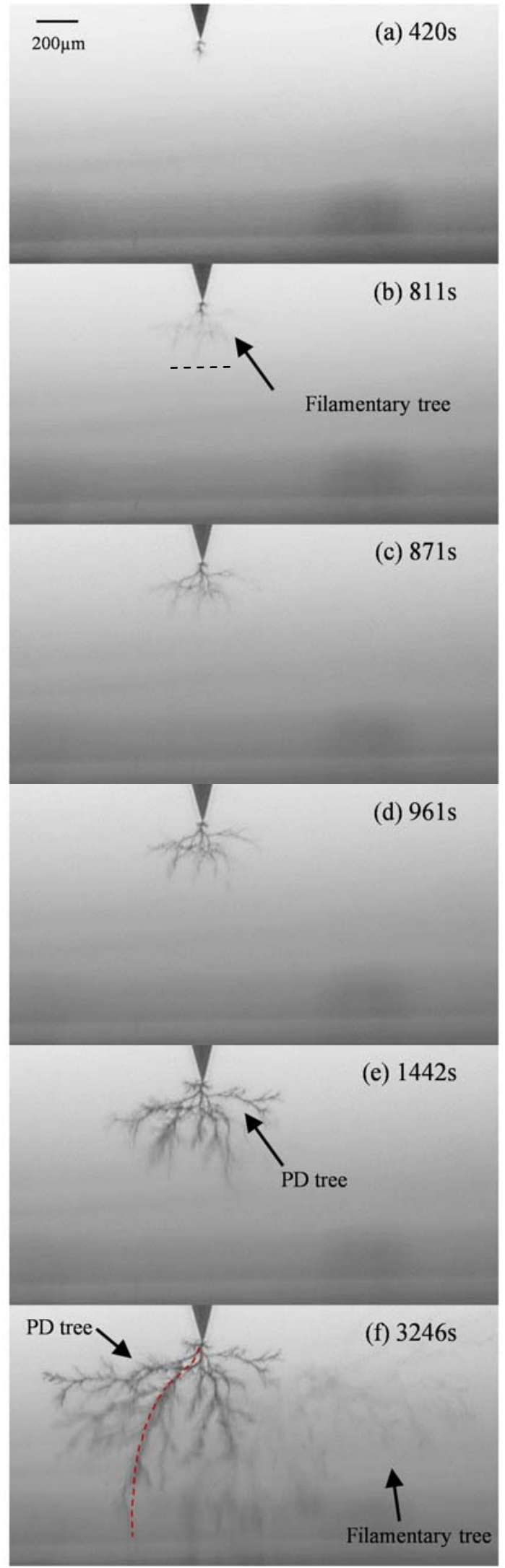

Figure 2. Two-dimensional projections of electrical trees at 6 time points. For clarity the black dashed line shows the furthest extent of the filamentary tree along the needle axis. Image (f) is the last recorded image before breakdown

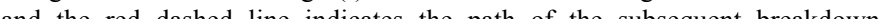

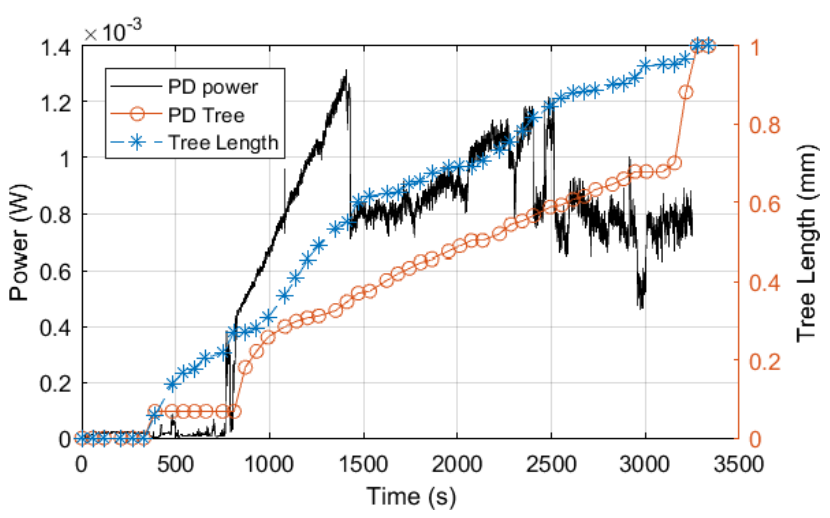

Figure 3. Power dissipation of partial discharges and the tree extension in the needle axis direction during the treeing process. The 'tree length' characterizes the vertical development of the entire tree structure, while the 'dark tree' only represents the PD tree length. A moving average over 50 points (1s duration) was applied to the PD power calculated per $20 \mathrm{~ms}$ (or power cycle).

\section{RESULTS}

\section{A. electrical treeing}

Figure 2 displays a typical tree structures developed during the treeing process. The two distinguishable tree structures, PD tree and filamentary tree, are of different gray levels/contrast in the 2-D images and therefore can be readily distinguished. Figure 3 shows the tree growth along the needle axis for the overall tree structure and the PD tree. In addition, Figure 3 also plots the corresponding PD power dissipation (which is the product of the apparent discharge magnitude $\mathrm{q}$ and the instantaneous voltage $\mathrm{V}$ at the discharge occurrence) in each $20 \mathrm{~ms}$ power cycle calculated using the following expression:

$$
P=\frac{1}{\Delta t} \sum V q
$$

A thick branch-like PD tree initially grew from the needle tip, reaching a length of $60 \mu \mathrm{m}$ after $390 \mathrm{~s}$ of constant $\mathrm{AC}$ voltage. Comparing Figure $2 a$ and Figure $2 b$, it can be seen that the initial PD tree ceased to grow thereafter, for a period of about $420 \mathrm{~s}$, but a filamentary tree continued to grow from the thicker PD tree tips. This period is also reflected in the tree length curves in Figure 3 between $390 \mathrm{~s}$ and $811 \mathrm{~s}$.

The growth of the PD tree restarted by transforming the existing filamentary tree channels. Between $810 \mathrm{~s}$ and $1000 \mathrm{~s}$, the PD tree grew by progressively developing the radius of the filamentary tree channels. It consequently appears as the dark tree propagating along existing filamentary tree paths as shown in Figure $2 \mathrm{~b}-2 \mathrm{~d}$. During this period, PD power increased almost linearly with time. At about $1000 \mathrm{~s}$, the filamentary tree is almost fully transformed into a dark tree as indicated by the tree length curves in Figure 3.

After the tree appears almost fully transformed to consist of thicker branches (in other words the filamentary tree has become a PD tree) at $1000 \mathrm{~s}$, the filamentary tree and PD tree continue to grow simultaneously. Comparing figure $1 \mathrm{~d}$ and $1 \mathrm{e}$, 
and the growth of tree length between $961 \mathrm{~s}$ and $1442 \mathrm{~s}$ in Figure 3 , the filamentary tree always developed ahead, and that tree continuously developed later increasing the PD tree length within the envelop established by the filamentary tree.

After the steep drop of PD power at $1430 \mathrm{~s}$, the growth rate of the filamentary tree slowed. In the meantime, the length of PD tree grew with a stable rate, similar to that of the filamentary tree. However filamentary trees continued to form ahead of the dark tree development.

The final image before breakdown, shown in Figure 1f, enables comparison of the morphologies of the trees. The filamentary tree, even at its maximum length, retains finer channels than the PD tree which is in the form of a classic branch tree. As shown in Figure 3, the filamentary tree propagated without acceleration when approaching the planner surface whereas PD tree triggered the runaway process to breakdown at a length of about $0.7 \mathrm{~mm}$. The breakdown channel is indicated by the red dashed line in Figure $2 \mathrm{f}$.

\section{B. PD Characteristics}

A linear PD power increase has been shown in Figure 3 between about $810 \mathrm{~s}$ and $1430 \mathrm{~s}$. This period reflected the transition of the PD tree formation. For more detailed PD characteristics during this stage, the maximum discharge magnitude in each positive and negative half cycle are presented in Figure 4 together with the PD frequency in each $20 \mathrm{~ms}$ cycle (a moving average over 50 points has been used). Figure 4 shows that only in this transient stage are the magnitudes of positive discharges greater than that of the negative charges. Moreover, no major variation can be identified from the Phase-Resolved-Partial-Discharge (PRPD) patterns as two time periods shown in Figure 5a and 5b. Surges in PD frequency were found at the beginning and end of this transient stage. Figure 5c illustrates the typical PRPD pattern within the surge at the end of the period. The increase in PD frequency is mainly due to discharges of small magnitude $(<50$ $\mathrm{pC})$. The disparity between positive and negative discharges started to reduce after $1400 \mathrm{~s}$ and after this transient period, as shown in Figure 5d, classical wing-like PD patterns formed with balanced bipolar discharges.

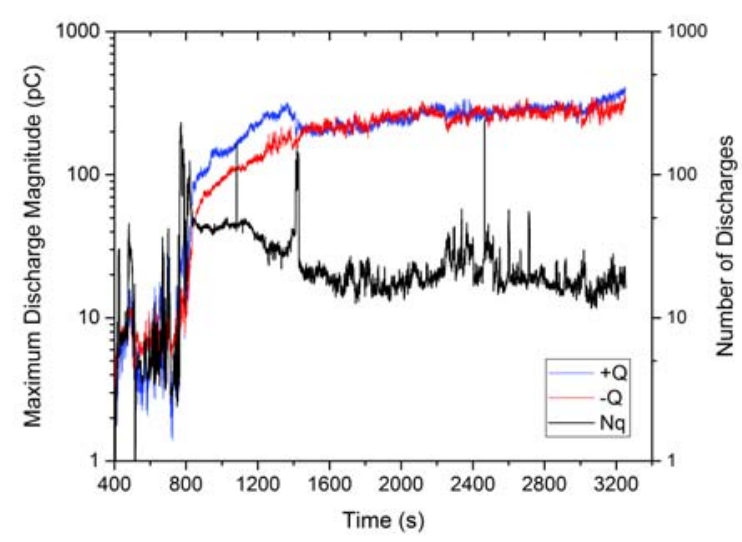

Figure 4. The maximum discharge magnitude in each half cycle (i.e. per 10 $\mathrm{ms}$ ) and the number of discharges $(\mathrm{Nq})$ in each $20 \mathrm{~ms}$ cycle. $+\mathrm{Q}: 0^{\circ}-180^{\circ},-\mathrm{Q}$ : $180^{\circ}-360^{\circ}$. For the sake of clarity, a moving average over 50 points $(1 \mathrm{~s}$ duration) was applied to all curves.

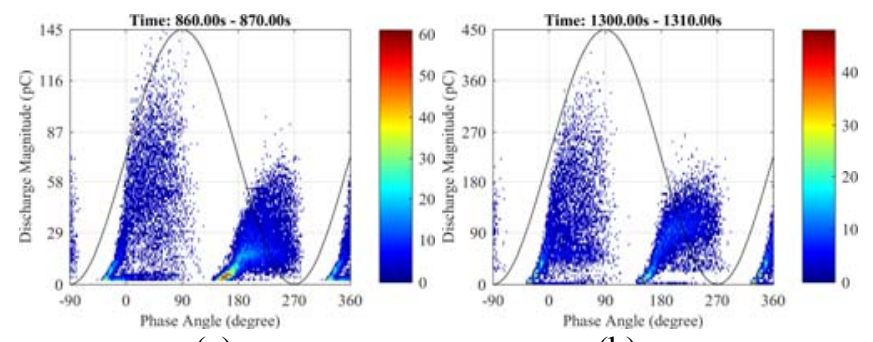

(a)

(b)

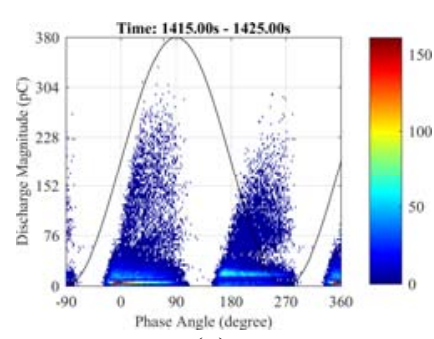

(c)

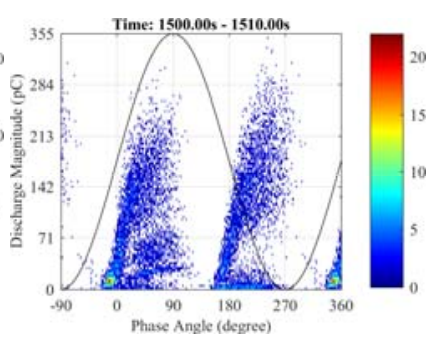

(d)
Figure 5. Phase resolved partial discharge patterns with color bar showing the charge density.

\section{DISCUSSION}

Although the filamentary tree has been reproducibly grown by the authors $[6,7]$, similar examples are rarely found in the literature. This may be attributed to the practical difficulties in monitoring and measuring their growth. Firstly, because the small channel radius makes the optical observation of the tree structures more difficult, and secondly because PD measurement and discharge luminescence detection is difficult. Certainly, if they existed, filamentary trees are unlikely to be seen in more translucent materials such as polyethylene. This and the low PD levels associated with filamentary trees suggests they may be unobserved in some cases. The transition from the filamentary to the PD tree may also be quite rapid, and so hard to distinguish.

A report of filamentary tree growth is found in Champion and Dodd's work [8] on electrical treeing in a glassy epoxy resin (Araldite CT 200). They reported that for AC stressed samples of needle-plane geometry, trees grew in 'young' specimens (23-33 days after samples were fully cured) of fine diameter $(\sim 1 \mu \mathrm{m})$ and low fractal dimension. Those features are consistent with the filamentary tree described here. Moreover the time to failure was reported to be extremely long for these 'young' samples. This is consistent with the result of this work, in that the filamentary tree fully traversed the insulation without catastrophic breakdown. Their work indicates the formation of the filamentary tree is determined by the material physical ageing as typical PD trees grew in older samples. However the work presented here shows that there is another factor influencing the transition from a filamentary tree to $\mathrm{PD}$ tree as both treeing process were observed in the same sample.

A theoretical model based on concepts of fracture mechanics proposed by Zeller and Schneider [4] can describe key features of filamentary tree growth. However the subsequent transition to a PD tree is not predicted in that model. However, developing from the concepts of electrofracture mechanics for filamentary tree growth, we 
propose an additional process for the observed conversion to PD treeing. In this process, discharge energy that is homogenously dissipated in the existing filamentary tree channels does not lead to the extension of the tree but increases the radius of the channels. The increase in radius consequently lowers the PD inception voltage and eventually triggers physically extended partial discharges from the places of highest electrical field gradient, i.e. at the needle tip. This increased partial discharge energy in turn further erodes the filamentary tree channels and thus results in the propagation of the PD tree with wider channels. The higher PD energy also changes the nature of the interaction between the discharges and the epoxy resin, developing conductive tree channels rather than insulating filamentary tree channels.

The polarity dependent discharge magnitude observed during the transition to the PD tree formation can be considered in the context of the polarity effect on DC treeing. It has been found that the voltage required for DC treeing is generally lower under positive DC voltages than under negative DC voltages $[9,10]$. This is normally attributed to the effect of polarity dependent space charge distribution in front of tree tips. However the work reported here shows that with the presence of a filamentary tree (which also can be regarded as an array of mechanical 'cracks'), the partial discharges within tree channels can be polarity dependent, which may be due to the distinct critical values for partial discharge inception and extinction under different voltage polarities. Therefore this gives an additional consideration to the effect of space charge at the tree tips.

\section{CONCLUSION}

An electrical treeing process has been described which contains two phases of growth distinguished by two types of tree structure: the filamentary tree and the PD tree. These are characterized by different channel radii (typically $1 \mu \mathrm{m}$ and 10 $\mu \mathrm{m}$ respectively). More importantly, it has been shown that the transition from a filamentary tree to a PD tree is associated with particular partial discharge activities. PD are of very low magnitude during filamentary tree development but larger and readily measured during $\mathrm{PD}$ tree growth.

A two-stage electrical tree propagation model is proposed in which filamentary trees firstly grow in length with channels of small radius $(\leq 1 \mu \mathrm{m})$, and this is followed by the PD tree growth in the form of widening the filamentary tree radii and changing the nature of its surface. The electrostatic energy released by the formation of a new short filamentary tree segment is small and is thus hard to measure. However increased partial discharge magnitudes observed during the PD tree growth is associated with enlarging existing channels but not creating new tree segments. Considering the filamentary trees are harder to observe visually than the PD trees, even in transparent materials, and the transition from a filamentary tree to a PD tree may be rapid, the existence of the filamentary tree may easily be missed.

Although PD measurement may not be able to effectively detect the existence of filamentary tree, PD signals are still valueable data to predict the insulation lifetime for the asset management because only the PD tree can trigger breakdown. Moreover, there may be some indications of PD tree initiation in measured PD signals. Specifically, during the early growth period, which started and ended with accompanying PD frequency surges, positive discharges have uniquely higher magnitude than negative charges.

\section{ACKNOWLEDGMENT}

The authors are grateful to the EPSRC for the financial support of this work through the project 'Towards Enhanced HVDC Cable Systems', EP/L021560/1.

\section{REFERENCES}

[1] L. A. Dissado and J. C. Fothergill, Electrical Degradation and Breakdown in Polymers: Institution of Engineering and Technology, 1992.

[2] S. J. Dodd, N. M. Chalashkanov, and J. C. Fothergill, "Partial discharge patterns in conducting and non-conducting electrical trees," in Solid Dielectrics (ICSD), 2010 10th IEEE International Conference on, 2010, pp. 1-4.

[3] K. Nakanishi, S. Hirabayashi, and Y. Inuishi, "Phenomena and Mechanisms of Tree Inception in Epoxy Resins," Electrical Insulation, IEEE Transactions on, vol. EI-14, pp. 306-314, 1979.

[4] H. R. Zeller and W. R. Schneider, "Electrofracture mechanics of dielectric aging," Journal of Applied Physics, vol. 56, pp. 455-459, 1984.

[5] H. P. Burgener, T. H. Teich, and K. Frohlich, "Simulations of partial discharges of small microcracks parallel to the electrical field in polymeric materials," in Annual Report Conference on Electrical Insulation and Dielectric Phenomena, 2002, pp. 146-150.

[6] S. Bahadoorsingh and S. M. Rowland, "An investigation of the harmonic impact on electrical tree growth," in Electrical Insulation (ISEI), Conference Record of the 2010 IEEE International Symposium on, 2010, pp. 1-5.

[7] I. Iddrissu, Z. Lv, and S. M. Rowland, "The dynamic character of partial discharge in epoxy resin at different stages of treeing," in 2016 IEEE International Conference on Dielectrics (ICD), 2016, pp. 728731.

[8] J. V. Champion and S. J. Dodd, "The effect of voltage and material age on the electrical tree growth and breakdown characteristics of epoxy resins," Journal of Physics D: Applied Physics, vol. 28, p. 398, 1995.

[9] I. Iddrissu, Z. Hualong, and S. M. Rowland, "Electrical tree growth in epoxy resin under DC voltages," in 2016 IEEE International Conference on Dielectrics (ICD), 2016, pp. 820-823.

[10] M. Fujii, M. Watanabe, I. Kitani, K. Arii, and K. Yoshino, "Fractal character of DC trees in polymethylmethacrylate," Electrical Insulation, IEEE Transactions on, vol. 26, pp. 1159-1162, 1991. 